Published in final edited form as:

Hepatology. 2007 November ; 46(5): 1476-1484. doi:10.1002/hep.21845.

\title{
Outcomes of Donor Evaluation in Adult-to-Adult Living Donor Liver Transplantation
}

\author{
James F. Trotter ${ }^{1}$, Karen A. Wisniewski ${ }^{2}$, Norah A. Terrault ${ }^{3}$, James E. Everhart ${ }^{4}$, Milan \\ Kinkhabwala ${ }^{5}$, Robert M. Weinrieb ${ }^{6}$, Jeffrey H. Fair ${ }^{7}$, Robert A. Fisher ${ }^{8}$, Alan J. Koffron ${ }^{9}$, \\ Sammy Saab ${ }^{10}$, Robert M. Merion ${ }^{2}$, and the A2ALL Study Group \\ ${ }^{1}$ Department of Surgery, University of Colorado, Denver, CO \\ ${ }^{2}$ Department of Surgery, University of Michigan, Ann Arbor, MI \\ ${ }^{3}$ Department of Medicine, University of California at San Francisco, San Francisco, CA \\ ${ }^{4}$ National Institute of Diabetes and Digestive and Kidney Diseases, National Institutes of Health, \\ Bethesda, MD \\ ${ }^{5}$ Department of Surgery, Columbia University Presbyterian Medical Center, New York, NY \\ ${ }^{6}$ Department of Psychiatry, University of Pennsylvania, Philadelphia, PA \\ ${ }^{7}$ Department of Surgery, University of North Carolina, Chapel Hill, NC \\ ${ }^{8}$ Department of Surgery, Medical College of Virginia Hospitals, Virginia Commonwealth \\ University, Richmond, VA \\ ${ }^{9}$ Department of Surgery, Northwestern University Medical School, Chicago, IL \\ ${ }^{10}$ Department of Medicine, University of California Los Angeles, Los Angeles, CA
}

\begin{abstract}
The purpose of donor evaluation for adult-to-adult living donor liver transplantation (LDLT) is to discover medical conditions that could increase the donor postoperative risk of complications and to determine whether the donor can yield a suitable graft for the recipient. We report the outcomes of LDLT donor candidates evaluated in a large multicenter study of LDLT. The records of all donor candidates and their respective recipients between 1998 and 2003 were reviewed as part of the Adult-to-Adult Living Donor Liver Transplantation Cohort Study (A2ALL). The outcomes of the evaluation were recorded along with demographic data on the donors and recipients. Of the 1011 donor candidates evaluated, $405(40 \%)$ were accepted for donation. The donor characteristics associated with acceptance $(P<0.05)$ were younger age, lower body mass index, and biological or spousal relationship to the recipient. Recipient characteristics associated with donor acceptance were younger age, lower Model for End-stage Liver Disease score, and shorter time from listing to first donor evaluation. Other predictors of donor acceptance included earlier year of evaluation and transplant center.
\end{abstract}

Copyright $\odot 2007$ by the American Association for the Study of Liver Diseases.

Address reprint requests to: James F. Trotter, M.D., University of Colorado Hospital, 1635 N. Ursula, Campus Box 154, Aurora, CO 80262. james.trotter@uchsc.edu; fax: 720-848-2246.

Presented in part at the World Transplant Congress, Boston, MA, July 2006.

This is publication number 5 of the Adult-to-Adult Living Donor Liver Transplantation Cohort Study.

Potential conflict of interest: Dr. Trotter is a consultant for and received grants from Novartis. He is on the speakers' bureau of and received grants from Roche. He is also on the speakers' bureau of Astellas. He also received grants from Cellzdirect, Aventis-Sanofi, and Abbott. 
Conclusion-Both donor and recipient features appear to affect acceptance for LDLT. These findings may aid the donor evaluation process and allow an objective assessment of the likelihood of donor candidate acceptance.

Donor evaluation is one of the most important aspects of adult-to-adult living donor liver transplantation (LDLT) ${ }^{1-3}$ The evaluation process is designed to reveal any condition that may increase the risk of complications for the donor. In addition, the transplant team should determine whether the donor will yield a suitable graft for the recipient. The evaluation process typically proceeds in a stepwise fashion so that unsuitable donors can be identified as early as possible. Acceptance of donors by the evaluating team implies that they have met all relevant medical, surgical, psychosocial, and informed consent criteria necessary to proceed with donor right hepatic lobectomy.

The Adult-to-Adult Living Donor Liver Transplantation Cohort Study (A2ALL) is a multicenter project funded by the National Institutes of Health to evaluate the outcomes of donors and recipients evaluated for and undergoing this procedure. Although designed with both retrospective and prospective phases, the data presented in this report are derived from the retrospective phase of A2ALL. There were three major goals of the analysis: (1) to describe the characteristics and acceptance rate of donor candidates; (2) to examine the evolution of donor selection over time; and (3) to identify factors that predict donor candidate acceptance.

\section{Patients and Methods}

\section{Study Subjects}

A2ALL includes nine US liver transplantation centers. ${ }^{4}$ Between January 1, 1998 and February 28, 2003, these centers evaluated 819 potential LDLT recipients, for whom 1011 donor candidates were evaluated. Two subsets of these potential donors have been previously reported in single-center evaluations of this topic. ${ }^{5,6}$ The donor evaluation is typically performed in a stepwise fashion beginning with basic laboratory tests, blood type confirmation, and, at many centers, a basic medical screening questionnaire. Study subject entry was defined as the date the donor candidate underwent a history and physical examination as part of the donor evaluation. Thereafter, the donor candidate was either accepted or not accepted for donation. Data were retrospectively collected on all donor and LDLT recipient candidates using standardized forms. For 389 of the potential recipients, an LDLT was performed.

\section{Donor Evaluation Outcomes}

The primary reason for not accepting donor candidates was categorized as donor or recipient related. Donor reasons included: (1) medical contraindication (diagnosis of medical condition that could increase the risk of short-term or long-term complications in the donor candidate, such as hypertension, abnormal blood chemistries, or chest radiograph); (2) anatomic considerations (findings on hepatic cross-sectional imaging that either increase the risk of hepatectomy in the donor candidate, for example, large hemangioma, or preclude the donor candidate from yielding a suitable graft, for example, significantly abnormal hepatic vasculature, or both); (3) donor candidate declined to donate; (4) hepatic histology showing steatosis greater than 10\%; or (5) psychosocial contraindications, such as active substance abuse. Recipient reasons included: (1) recipients who declined the donor's offer or (2) recipients who had a change in condition precluding the feasibility of or need for LDLT [improvement, deterioration, receipt of a deceased donor liver transplant (DDLT), or death].

To compare candidates wait-listed for liver transplantation who had a potential living donor with those who did not at the 9 A2ALL centers, we compared potential LDLT recipients 
with the complement of DDLT-listed candidates in the Scientific Registry of Transplant Recipients (SRTR) database, under a data use agreement. DDLT transplant candidates included those listed for transplantation between the date of their center's LDLT program initiation and February 28, 2003 at each A2ALL center, but who did not have a living donor evaluated. In addition, SRTR data were used to supplement A2ALL data where available.

The time from a candidate's listing to the date of his/her first potential donor's evaluation was calculated in days and categorized by quartiles. We found no significant difference in donor acceptance probabilities between the second through fourth quartiles, so this variable was dichotomized (before day 23 versus day 23 or after) for further analyses. Calendar time effects on donor acceptance were tested using 1998 to 2000 versus 2001 to 2003.

The Model for End-stage Liver Disease score (MELD) was calculated for the LDLT candidates at the time of donor evaluation as previously described. ${ }^{7,8}$ Laboratory-based MELD was calculated for DDLT candidates listed after September 2001, when MELD component reporting became a requirement. For statistical comparisons of MELD scores between LDLT and DDLT candidates, those of LDLT candidates were restricted to the MELD era.

Body mass index (BMI) of recipient and donor candidates was calculated as weight in kilograms divided by height in meters squared $\left(\mathrm{kg} / \mathrm{m}^{2}\right)$ at the time of evaluation and categorized as low $\left(<18.5 \mathrm{~kg} / \mathrm{m}^{2}\right)$, normal $\left(18.5-24.9 \mathrm{~kg} / \mathrm{m}^{2}\right)$, overweight $\left(25-29.9 \mathrm{~kg} / \mathrm{m}^{2}\right)$, or obese $\left(230 \mathrm{~kg} / \mathrm{m}^{2}\right) .{ }^{9}$ In the logistic regression analysis, the combined group of underweight and normal weight served as the reference group.

A history of adverse events or diseases in potential recipients that had the potential to confound the likelihood of donor acceptance, such as coronary artery disease, diabetes mellitus, the need for mechanical ventilation, and renal failure, were collected for the recipient candidates at the time of donor evaluation.

The study was approved by the institutional review boards and privacy boards of the University of Michigan Data Coordinating Center and each of the 9 participating transplant centers.

\section{Statistical Analysis}

Demographic characteristics of potential donors were tabulated by donor acceptance status. Demographic and medical characteristics of potential recipients were tabulated by donor acceptance status and were compared with DDLT candidates not considered for LDLT at the 9 A2ALL centers during the same time period. Donor-related and recipient-related reasons for donors not being accepted, as well as information on aborted transplant procedures, were tabulated.

Logistic regression analysis was used to model the probability of donor acceptance as a function of donor and recipient characteristics. Robust (sandwich estimator) variances were used to adjust for possible correlation among potential donors of the same recipient. Twoway interactions were tested and not found to be significant. The strength of overall covariate prediction was assessed by the c-statistic (based on the area under the receiver operating characteristic curve), with a value of 0.70 or greater considered to provide acceptable discrimination. ${ }^{10}$ Relative covariate predictive ability was assessed by the change in the c-statistic value ( $\Delta \mathrm{c}$-statistic) when a covariate was removed from the model. All analyses were performed using SAS version 9.1. 


\section{Role of the Funding Sources}

The National Institutes of Health project scientist participated in study design and analysis and interpretation of data. The Health Resources and Services Administration and American Society of Transplant Surgeons had no direct involvement in the study.

\section{Results}

The characteristics of living donor candidates who were accepted and not accepted are depicted in Table 1. The overall proportion accepted (accepted donor candidates divided by all donor candidates) was 405 of 1011 (40\%). There were no significant differences in the age, sex, ethnicity or race of accepted donor candidates compared with those who were not accepted. Accepted donors had significantly lower body weight (by $5 \mathrm{~kg}$ ) and BMI ( $26 \pm 4.2$ versus $28 \pm 4.8$; both $P<0.0001$ ) than candidates who were not accepted. Accepted donor candidates were significantly more likely to be an offspring, sibling, or spouse of the recipient $(P<0.0001)$. The most common donor candidate was an offspring of the recipient (31\% of all donor candidates; $34 \%$ of accepted donor candidates). For some recipients, several potential donors were evaluated. The probability of donor acceptance was higher for the first donor evaluated (41\%) than for the second $(35 \%)$ or subsequent $(30 \%)$, but these differences were not statistically significant $(P=0.16)$. The overall rate of donor acceptance was significantly higher during the early experience (47\% from 1998-2000) compared with later experience (35\% from 2001-2003; $P=0.0002$ ).

Demographics of the 819 LDLT recipient candidates, by donor acceptance status, and 7358 waitlisted DDLT candidates not considered for LDLT from the 9 A2ALL centers are shown in Table 2. Among the LDLT recipient candidates, those who had at least 1 donor accepted for donation were younger, had a lower BMI, a lower prevalence of ascites, lower MELD scores, and significantly shorter times from listing to first donor evaluation. The number of donors evaluated for each recipient was similar between the LDLT candidates who did and did not have a donor accepted.

Differences between LDLT candidates with or without a donor accepted were substantially less than differences between all LDLT candidates and DDLT candidates (Table 2).

Compared with all DDLT candidates, LDLT candidates were significantly more likely to be women and white, and to weigh less and have lower BMI. Potential LDLT recipients were significantly more likely to have cirrhosis caused by hepatitis $\mathrm{C}$ virus, hepatocellular carcinoma, other primary hepatic malignancies, and cholestatic disorders and less likely to have fulminant hepatic failure. LDLT candidates were no less likely to have alcoholic liver disease than DDLT candidates. After February 2002, potential LDLT recipients had similar MELD scores at the time of first donor evaluation compared with those among DDLT candidates at the time of listing $(16.0 \pm 6.7$ versus $15.8 \pm 8.3 ; P=0.62)$. However, LDLT candidates were significantly more likely to have had a history of variceal hemorrhage, or treatment with a transjugular intrahepatic portosystemic shunt. LDLT candidates were significantly less likely to have had a history of prior upper abdominal surgery or to have been in an intensive care unit at the time of donor evaluation compared with DDLT candidates at the time of listing.

Table 3 shows the disposition of donor candidate evaluations. Sixty percent of evaluated donors were not accepted, a medical contraindication being the most common reason $(\mathrm{n}=$ 173). The most common recipient-related reason that donors were not accepted was availability of a DDLT before LDLT donation. There were no significant differences in the distributions of donor-related or recipient-related reasons for rejection of donor candidates in 2001 to 2003 compared with 1998 to $2000(P=0.48)$. 
Twelve accepted donor candidates were taken to the operating room with the intent of donation, but the procedure was not completed ("aborted donation"). One additional accepted donor underwent right hepatic lobectomy, but the graft was not transplanted into the intended recipient. Nine of the "aborted donation" cases occurred later in the LDLT experience between 2001 and 2003.

A logistic regression model was fitted to estimate the adjusted odds of donor acceptance associated with putative predictive factors (Table 4). With regard to donor age, candidates between 18 and 40 years were the most likely to be accepted. Accepted donors were less likely to be overweight (BMI, 25.0-29.9 $\mathrm{kg} / \mathrm{m}^{2}$ ) or obese (BMI $\geq 30.0 \mathrm{~kg} / \mathrm{m}^{2}$ ) and were more likely to be family members (biological or spousal relationship). Potential donors evaluated earlier in a center's LDLT experience were twice as likely to be accepted for donation $(P<$ $0.0001)$. Younger potential recipients and those with lower MELD scores were significantly more likely to have their donor candidates accepted. Donor candidates were also more likely to be accepted if the recipient had been listed for DDLT less than 23 days before first donor evaluation. The medical center of evaluation was also a significant predictor of acceptance, with a 10 -fold range of odds ratios (OR 0.26 to 2.4 versus the average donor acceptance over the A2ALL centers, $P<0.0001)$.

The overall c-statistic (area under the receiver operating characteristic curve) for the model predicting donor acceptance was 0.731 . The strongest predictors of donor acceptance included (in descending order): medical center of evaluation $(\Delta c$-statistic $=0.060)$, donor BMI $(\Delta$ c-statistic $=0.022)$, year of donor evaluation $(\Delta c$-statistic $=0.012)$, recipient MELD score $(\Delta \mathrm{c}$-statistic $=0.010)$, time from recipient listing to first donor evaluation $(\Delta \mathrm{c}$-statistic $=0.009)$, recipient age $(\Delta c$-statistic $=0.006)$, donor-recipient relatedness $(\Delta c$-statistic $=$ $0.005)$, and donor age $(\Delta \mathrm{c}$-statistic $=0.003)$.

\section{Discussion}

This analysis provides perhaps the largest collective experience documenting the outcomes of donor evaluation for LDLT among adults. Several of the results deserve comment. Although it was anticipated that donor acceptance might have increased with greater experience in donor evaluations, in fact the donor acceptance rate declined with greater center experience. There are several likely explanations for the decreased rate of acceptance over time. First, when LDLT was initially offered at each center, hundreds of patients were already listed for deceased donor transplantation, some of whom were ideal candidates for LDLT. Early in the experience of LDLT, a proportionally higher number of the recipients with ideal donors may have been identified and were likely accepted for LDLT at a higher rate. Once these ideal recipient-donor pairs were transplanted, the remaining donor candidates were rejected at a higher rate during the evaluation. Second, transplant centers may have become more conservative in their approach toward LDLT after the highly publicized death of a living donor in 2001 in the United States. After this catastrophic event, some centers may have become more conservative in their selection of donors in an attempt to minimize the risk of unfavorable donor outcomes. The overall reduction in the number of LDLT in the United States after 2001 by approximately $50 \%$ may reflect a more restrained approach toward the procedure. ${ }^{11}$ Third, the institution of the MELD score as the basis for deceased donor liver allocation may have impacted LDLT. After February 2002, when MELD was introduced, fewer patients died on the waiting list, likely because of expedited DDLT. Between 2001 and 2003, we noted a higher proportion of LDLT candidates who had DDLT during the course of the donor's evaluation.

As expected, donor candidates with higher BMI were much less likely to be accepted as donors. Overweight and obese patients are higher-risk living liver donors because of greater 
likelihood of hepatic steatosis and medical problems (diabetes, hypertension, and heart disease), which could increase the postoperative complications. ${ }^{12,13}$ However, recent data have shown that selected obese candidates may successfully undergo donation without evidence of increased complications. ${ }^{14}$ Accepted donor candidates were more likely to be related to the recipient (including spouses) than rejected candidates. The most obvious explanation is that the related candidates may have demonstrated a greater interest and understanding of the donation procedure and therefore presented themselves as better candidates.

Changes in the recipient's condition were an important determinant of whether donor candidates were accepted for operation. Thirteen percent of donor candidates were not accepted because of a change in the recipient's condition, the most common of which was receipt of a DDLT. In these cases, the DDLT occurred before completion of the donor evaluation. Acceptance as a living donor did not ensure that the patient would undergo the operation. Thirteen approved donor candidates were taken to the operating room, but a donor hepatectomy was not completed because of intraoperative recipient death or unexpected findings in the donor or recipient. Each of these cases represents a failure of the donor or recipient evaluation process.

The logistic regression analysis identified important predictors of donor acceptance. Interestingly, several of the strongest predictors of donor acceptance were not related to any specific donor factors: medical center of evaluation, year of evaluation, recipient age, and recipient MELD. Perhaps younger, less sick recipient candidates evaluated early in the experience at specific centers had more favorable donor candidates. Alternatively, donor candidates may not have been evaluated independently of the recipient characteristics. That is, donor candidates may have been viewed more favorably if their recipient was deemed a better candidate. This issue requires further evaluation. Accepted donors were primarily the first donors evaluated for a given recipient because of the fact that these donors made up the majority of the subject population. However, the percentage of first donors accepted was only slightly higher than that of second and subsequent donors.

We were somewhat surprised at the large variation in the likelihood of donor acceptance based on the center of evaluation, and the explanation for this finding is not entirely clear. These variations in acceptance rates may be attributable to subtle and unmeasured differences in how transplant centers evaluate donors. That is, there may be important differences in how donor candidates were prescreened before the formal donor evaluation, which was the entry point for the A2ALL study. In addition, some of the difference may have been attributable to the small number of donor evaluations performed at some of the centers.

LDLT candidates differed substantially from DDLT candidates by demographic factors, disease cause, and severity of illness. This difference was much greater than differences between LDLT candidates with or without successful donor evaluation. This is not surprising, given the effect of recipient characteristics on the likelihood of a potential LDLT donor being accepted. Importantly, the differences between DDLT and LDLT candidates point to potential problems in comparisons of transplant outcomes between groups of patients who may differ in fundamental ways.

There are several notable weaknesses of our analysis. Most important, the retrospective nature of this study precluded complete collection of data on all candidates. This was most apparent in the proportion with missing demographic data among donor candidates who were not accepted. Because the study was conducted up to 5 years after their evaluation, many of the donor candidates were no longer in contact with the transplant center. 
Therefore, there was no opportunity to obtain missing data values in these candidates. In contrast, the accepted living donor candidates, almost all of whom proceeded to donor hepatectomy, often had ongoing relationships with the transplant center, which facilitated data collection. Identification of the precise reason for rejecting donor candidates may have been imperfect when determined in retrospect. For example, a donor may have had extensive hepatic steatosis identified retrospectively as the indication for nonacceptance, but elected not to donate independently of the biopsy findings. Another significant weakness of this study is that we may not have captured the complexities of the donor evaluation process. Our analysis allowed the selection of only 1 of a limited number of reasons for donor nonacceptance when in some cases the reasons may have been multifactorial. For example, a donor candidate may have had a large hepatic hemangioma and abnormal electrocardiogram (either of which would preclude donation), but only a single reason was recorded for this study. Finally, although the evaluation process at each center is similar, there are likely subtle differences in the identification and selection of donors and recipients that could lead to differences in outcomes of the donation process. Because of the nature of our analysis we were not able to capture the effect of these differences on donor candidate outcomes.

One of the weaknesses of this study is that there are likely important differences in the subtle details in each center's approach to LDLT. Specifically, some centers may have been more or less aggressive in recruiting patients for the procedure. In addition, the specific approach to the donor evaluation, type of cross-sectional imaging used in assessment of donor anatomy, and use of the liver biopsy in donor evaluation likely varied slightly between the centers. We acknowledge that these subtle differences may not have been accounted for in our analysis and could result in slight differences in the donor acceptance rate between the 9 participating centers.

In summary, we have described the outcomes in a large group of donor candidates for LDLT. We found that (1) the overall rate of acceptance for donor candidates was $40 \%$; (2) the acceptance rate has dropped over time; and (3) the strongest predictors of donor acceptance, in decreasing order of importance, were center of evaluation, donor BMI, year of evaluation, recipient MELD score, days from listing to first donor evaluation, recipient age, donor-recipient relatedness, and donor age. These findings may aid the donor evaluation process and allow an objective assessment of the likelihood of donor candidate acceptance.

\section{Acknowledgments}

The following individuals were instrumental in the planning, conduct, or care of patients enrolled in this study at each of the participating institutions as follows:

Columbia University Health Sciences, New York, NY (DK62483): principal investigator (PI): Jean C. Emond, MD; Co-PI: Robert S. Brown Jr., MD, MPH; Study Coordinators: Rudina Odeh-Ramadan, PharmD; Taruna Chawla, $\mathrm{MD}$

Northwestern University, Chicago, IL (DK62467): PI: Michael M.I. Abecassis, MD, MBA; Co-PI: Andres Blei, MD; Study Coordinator: Patrice Al-Saden, RN, CTCC

University of Pennsylvania Health System, Philadelphia, PA (DK62494): PI: Abraham Shaked, MD, PhD; Co-PI: Kim M. Olthoff, MD; Study Coordinators: Mary Kaminski, PA-C; Mary Shaw, RN, BBA

University of Colorado Health Sciences Center, Denver, CO (DK62536): PI: James F. Trotter, MD; Co-PI: Igal Kam, MD; Study Coordinators: Scott Heese, BA; Carlos Garcia, BS

University of California Los Angeles, Los Angeles, CA (DK62496): PI: Rafik Mark Ghobrial, MD, PhD; Co-PI: Ronald W. Busuttil, MD, PhD; Study Coordinator: Lucy Artinian, RN, MN 
University of California San Francisco, San Francisco, CA (DK62444): PI: Chris E. Freise, MD, FACS; Co-PI: Norah A. Terrault, MD; Study Coordinator: Dulce MacLeod, RN

University of Michigan Medical Center, Ann Arbor, MI (DK62498): PI: Robert M. Merion, MD; DCC Staff: Anna S.F. Lok, MD; Akinlolu O. Ojo, MD, PhD; Brenda W. Gillespie, PhD; Douglas R. Armstrong, RN, MS; Margaret Hill-Callahan, BS, LSW; Terese Howell, BS; Lan Tong, MS; Tempie H. Shearon, MS; Karen A. Wisniewski, MPH; Monique Lowe, BS

University of North Carolina, Chapel Hill, NC (DK62505): PI: Jeffrey H. Fair, MD; Study Coordinator: Carrie A. Nielsen, MA

University of Virginia (DK62484): PI: Carl L. Berg, MD; Co-PI: Timothy L. Pruett, MD; Study Coordinator: Jaye Davis, RN

Medical College of Virginia Hospitals, Virginia Commonwealth University, Richmond, VA (DK62531): PI: Robert A. Fisher, MD, FACS; Co-PI: Mitchell L. Shiffman, MD; Study Coordinators: Ede Fenick, RN; April Ashworth, RN

National Institute of Diabetes and Digestive and Kidney Diseases, Division of Digestive Diseases and Nutrition, Bethesda, MD: James E. Everhart, MD; Leonard B. Seeff, MD; Patricia R. Robuck, PhD; Jay H. Hoofnagle, MD

Supplemental data included here have been supplied by Arbor Research Collaborative for Health as the contractor for the SRTR. The interpretation and reporting of these data are the responsibility of the author(s) and in no way should be seen as an official policy of or interpretation by the SRTR or the U.S. Government.

Supported in part by the National Institutes of Health (NIDDK grant numbers U01-DK62536, U01-DK62444, U01DK62467, U01-DK62483, U01-DK62484, U01-DK62494, U01-DK62496, U01-DK62498, U01-DK62505, U01DK62531), the American Society of Transplant Surgeons, and the U.S. Department of Health and Human Services, Health Resources and Services Administration.

\section{Abbreviations}

A2ALL Adult-to-Adult Living Donor Liver Transplantation Cohort Study

BMI body mass index

DDLT deceased donor liver transplant

LDLT living donor liver transplantation

MELD Model for End-stage Liver Disease score

SRTR Scientific Registry of Transplant Recipients

\section{References}

1. Brandhagen D, Fidler J, Rosen C. Evaluation of the donor liver for living donor liver transplantation. Liver Transpl. 2003; 9(10 Suppl 2):S16-S28. [PubMed: 14528424]

2. Rudow DL, Brown RS Jr. Evaluation of living liver donors. Prog Transplant. 2003; 13:110-116. [PubMed: 12841517]

3. Trotter JF. Selection of donors for living donor liver transplantation. Liver Transpl. 2003; 9(10 Suppl 2):S2-S7. [PubMed: 14528421]

4. Olthoff KM, Merion RM, Ghobrial RM, Abecassis MM, Fair JH, Fisher RA, et al. Outcomes of 385 adult-to-adult living donor liver transplant recipients: a report from the A2ALL consortium. Ann Surg. 2005; 242:314-325. [PubMed: 16135918]

5. Verna EC, Hunt KH, Renz JF, Rudow DL, Hafliger S, Dove LM, et al. Predictors of candidate maturation among potential living donors. Am J Transplant. 2005; 5:2549-2554. [PubMed: 16162206]

6. Trotter JF, Campsen J, Bak T, Wachs M, Forman L, Everson G, et al. Outcomes of donor evaluations for adult-to-adult right hepatic lobe living donor liver transplantation. Am J Transplant. 2006; 6:1882-1889. [PubMed: 16889543] 
7. [Accessed June 21, 2007] MELD-PELD calculator. Available at: http://www.unos.org/resources/ meldPeldCalculator.asp

8. Freeman RB, Wiesner RH, Roberts JP, McDiarmid S, Dykstra DM, Merion RM. Improving liver allocation: MELD and PELD. Am J Transplant. 2004; 4(Suppl 9):114-131. [PubMed: 15113360]

9. Centers for Disease Control and Prevention. [Accessed June 21, 2007] Body mass index. Available at: www.cdc.gov/nccdphp/dnpa/bmi/adult_BMI/about_adult_BMI.htm

10. Hosmer, DW.; Lemeshow, S. Applied Logistic Regression. 2nd ed. John Wiley \& Sons; New York: 2000.

11. Trotter JF. Living donor liver transplantation: is the hype over? J Hepatol. 2005; 42:20-25. [PubMed: 15629502]

12. Rinella ME, Alonso E, Rao S, Whitington P, Fryer J, Abecassis M, et al. Body mass index as a predictor of hepatic steatosis in living liver donors. Liver Transpl. 2001; 7:409-414. [PubMed: 11349260]

13. Ryan CK, Johnson LA, Germin BI, Marcos A. One hundred consecutive hepatic biopsies in the workup of living donors for right lobe liver transplantation. Liver Transpl. 2002; 8:1114-1122. [PubMed: 12474149]

14. Moss J, Lapointe-Rudow D, Renz JF, Kinkhabwala M, Dove LM, Gaglio PJ, et al. Select utilization of obese donors in living donor liver transplantation: implications for the donor pool. Am J Transplant. 2005; 5:2974-2981. [PubMed: 16303013] 
Table 1

Characteristics of A2ALL Potential Donors (Evaluation Years 1998-2003)

\begin{tabular}{|c|c|c|c|c|}
\hline \multirow[b]{2}{*}{ Characteristic } & \multirow{2}{*}{$\frac{\text { Overall }(\mathrm{n}=1,011)}{\text { Mean }(\mathrm{SD} ; \text { range) or } \mathrm{N}(\%)}$} & $\begin{array}{l}\text { Donors Who Were } \\
\text { Accepted }(n=405) \\
\end{array}$ & $\begin{array}{c}\text { Donors Who Were Not } \\
\text { Accepted }(\mathrm{n}=606)\end{array}$ & \multirow[b]{2}{*}{$P$ Value } \\
\hline & & Mean (SD; range) or N (\%) & Mean (SD; range) or N (\%) & \\
\hline Age & $37(10.1 ; 18-59)$ & $37(9.6 ; 18-59)$ & $38(10.3 ; 18-59)$ & 0.0846 \\
\hline Age (categories) & & & & 0.1676 \\
\hline Age $18-39$ & $577(57 \%)$ & $244(60 \%)$ & $333(55 \%)$ & \\
\hline Age $40-49$ & $301(30 \%)$ & $116(29 \%)$ & $185(31 \%)$ & \\
\hline Age $\geq 50$ & $130(13 \%)$ & $44(11 \%)$ & $86(14 \%)$ & \\
\hline Sex & & & & 0.3430 \\
\hline Female & $446(44 \%)$ & $186(46 \%)$ & $260(43 \%)$ & \\
\hline Male & $565(56 \%)$ & $219(54 \%)$ & $346(57 \%)$ & \\
\hline Ethnicity * & & & & 0.7923 \\
\hline Hispanic/Latino & $171(17 \%)$ & $68(17 \%)$ & $103(18 \%)$ & \\
\hline Non-Hispanic/Non-Latino & $820(83 \%)$ & $335(83 \%)$ & $485(82 \%)$ & \\
\hline Race * & & & & 0.1129 \\
\hline White & $894(90 \%)$ & $366(91 \%)$ & $528(89 \%)$ & \\
\hline African-American & $53(5 \%)$ & $15(4 \%)$ & $38(6 \%)$ & \\
\hline Other & $46(5 \%)$ & $22(5 \%)$ & $24(4 \%)$ & \\
\hline Height $(\mathrm{cm})$ & $173(10.1 ; 145-211)$ & $173(10.0 ; 150-203)$ & $173(10.1 ; 145-211)$ & 0.9234 \\
\hline Weight (kg) & $81(16.7 ; 41-146)$ & $78(15.3 ; 43-146)$ & $83(17.4 ; 41-146)$ & $<0.0001$ \\
\hline Body mass index $\left(\mathrm{kg} / \mathrm{m}^{2}\right)$ & $27(4.6 ; 16-57)$ & $26(4.2 ; 17-57)$ & $28(4.8 ; 16-50)$ & $<0.0001$ \\
\hline Body mass index (categories) & & & & $<0.0001$ \\
\hline $\mathrm{BMI}<18.5$ & $11(1 \%)$ & $6(1 \%)$ & $5(1 \%)$ & \\
\hline BMI 18.5-24.9 & $296(29 \%)$ & $148(37 \%)$ & $148(24 \%)$ & \\
\hline BMI 25.0-29.9 & $408(40 \%)$ & $182(45 \%)$ & $226(37 \%)$ & \\
\hline $\mathrm{BMI} \geq 30$ & $208(21 \%)$ & $61(15 \%)$ & $147(24 \%)$ & \\
\hline Missing & $88(9 \%)$ & $8(2 \%)$ & $80(13 \%)$ & \\
\hline Relatedness to recipient & & & & $<0.0001$ \\
\hline \multicolumn{5}{|l|}{ Biologically related } \\
\hline Parent & $27(3 \%)$ & $9(2 \%)$ & $18(3 \%)$ & \\
\hline Offspring & $317(31 \%)$ & $139(34 \%)$ & $178(29 \%)$ & \\
\hline Sibling & $210(21 \%)$ & $92(23 \%)$ & $118(19 \%)$ & \\
\hline Other biological & $95(9 \%)$ & $35(9 \%)$ & $60(10 \%)$ & \\
\hline \multicolumn{5}{|l|}{ Not biologically related } \\
\hline Spouse & $86(9 \%)$ & $51(13 \%)$ & $35(6 \%)$ & \\
\hline Other nonbiological & $223(22 \%)$ & $78(19 \%)$ & $145(24 \%)$ & \\
\hline Unknown/Missing & $53(5 \%)$ & $1(<1 \%)$ & $52(9 \%)$ & \\
\hline $\begin{array}{l}\text { Order of donor evaluated for } \\
\text { their recipient candidate }\end{array}$ & & & & 0.1589 \\
\hline 1st donor evaluated & $819(81 \%)$ & $339(84 \%)$ & $480(79 \%)$ & \\
\hline
\end{tabular}




\begin{tabular}{lccccc}
\hline & Overall $(\mathbf{n = 1 , 0 1 1})$ & & $\begin{array}{c}\text { Donors Who Were } \\
\text { Accepted (n= 405) }\end{array}$ & & $\begin{array}{c}\text { Donors Who Were Not } \\
\text { Accepted (n= 606) }\end{array}$ \\
\cline { 2 - 3 } Characteristic & Mean (SD; range) or N $(\boldsymbol{\%})$ & Mean (SD; range) or N $(\%)$ & Mean (SD; range) or N (\%) & $\boldsymbol{P}$ Value \\
\hline 2nd donor evaluated & $147(15 \%)$ & $52(13 \%)$ & $95(16 \%)$ \\
3rd-7th donor evaluated & $43(4 \%)$ & $13(3 \%)$ & $30(5 \%)$ \\
\hline
\end{tabular}

Missing at most $2 \%$. 
Table 2

Characteristics of A2ALL Potential LDLT Recipients by Donor Acceptance Status Compared With DDLT Waitlist Candidates Not Considered for LDLT at A2ALL Centers

\begin{tabular}{|c|c|c|c|c|c|}
\hline \multirow[t]{2}{*}{ Characteristic } & \multirow{2}{*}{$\begin{array}{c}\text { Potential Recipients } \\
\text { With } \\
\text { at Least One Donor } \\
\text { Accepted }(\mathrm{n}=\mathbf{4 0 1}) \\
\begin{array}{c}\text { Mean (SD) or } \\
\text { Percent }\end{array}\end{array}$} & \multirow{2}{*}{$\begin{array}{c}\begin{array}{c}\text { Potential Recipients } \\
\text { With } \\
\text { No Donors Accepted } \\
(\mathrm{n}=\mathbf{4 1 8})\end{array} \\
\begin{array}{c}\text { Mean (SD) or } \\
\text { Percent }\end{array}\end{array}$} & \multirow[t]{2}{*}{$\begin{array}{c}P \\
\text { Value }^{\dagger}\end{array}$} & \multirow{2}{*}{$\begin{array}{c}\begin{array}{c}\text { DDLT Waitlist } \\
\text { Candidates } \\
\text { Not Considered for } \\
\text { LDLT } \\
(\mathbf{n}=7,358)\end{array} \\
\begin{array}{c}\text { Mean (SD) or } \\
\text { Percent }\end{array}\end{array}$} & \multirow[t]{2}{*}{$P$ Value } \\
\hline & & & & & \\
\hline Age & $49.0(10.9)$ & $51.1(9.7)$ & 0.0033 & $50.7(10.3)$ & 0.0635 \\
\hline Age (categories) & & & 0.0290 & & 0.2271 \\
\hline Age 18-29 & $7 \%$ & $4 \%$ & & $4 \%$ & \\
\hline Age $30-49$ & $42 \%$ & $37 \%$ & & $41 \%$ & \\
\hline Age $\geq 50$ & $51 \%$ & $59 \%$ & & $54 \%$ & \\
\hline Sex & & & 0.4905 & & 0.0230 \\
\hline Female & $41 \%$ & $44 \%$ & & $39 \%$ & \\
\hline Male & $59 \%$ & $56 \%$ & & $61 \%$ & \\
\hline Ethnicity ${ }^{*}$ & & & 0.6390 & & 0.0708 \\
\hline Hispanic/Latino & $20 \%$ & $19 \%$ & & $17 \%$ & \\
\hline Non-Hispanic/Non-Latino & $80 \%$ & $81 \%$ & & $83 \%$ & \\
\hline Race * & & & 0.0834 & & 0.0005 \\
\hline White & $90 \%$ & $89 \%$ & & $84 \%$ & \\
\hline African-American & $3 \%$ & $7 \%$ & & $7 \%$ & \\
\hline Asian & $4 \%$ & $2 \%$ & & $6 \%$ & \\
\hline Other & $3 \%$ & $2 \%$ & & $3 \%$ & \\
\hline Height $(\mathrm{cm})$ & $171.3(10.8)$ & $170.9(9.8)$ & 0.6143 & $171.0(11.0)$ & 0.7865 \\
\hline Weight $(\mathrm{kg})$ & $78.5(18.2)$ & $80.4(17.8)$ & 0.1296 & $82.7(20.4)$ & $<0.0001$ \\
\hline Body mass index $\left(\mathrm{kg} / \mathrm{m}^{2}\right)$ & $26.7(5.3)$ & $27.4(5.2)$ & 0.0526 & $28.5(11.6)$ & 0.0005 \\
\hline Body mass index (categories) & & & 0.0898 & & $<0.0001$ \\
\hline $\mathrm{BMI}<18.5$ & $3 \%$ & $2 \%$ & & $2 \%$ & \\
\hline BMI 18.5-24.9 & $38 \%$ & $35 \%$ & & $28 \%$ & \\
\hline BMI 25.0-29.9 & $38 \%$ & $34 \%$ & & $31 \%$ & \\
\hline BMI $\geq 30$ & $20 \%$ & $28 \%$ & & $29 \%$ & \\
\hline Missing & $1 \%$ & $1 \%$ & & $11 \%$ & \\
\hline Education level ${ }^{*}$ & & & 0.2362 & & 0.0003 \\
\hline None & $<1 \%$ & $0 \%$ & & $1 \%$ & \\
\hline Grade/High School (0-12) & $35 \%$ & $41 \%$ & & $44 \%$ & \\
\hline Tech/Bachelor/Graduate & $49 \%$ & $45 \%$ & & $40 \%$ & \\
\hline Unknown & $16 \%$ & $14 \%$ & & $14 \%$ & \\
\hline \multicolumn{6}{|c|}{$\begin{array}{l}\text { Diagnosis at enrollment and listing (more } \\
\text { than } \\
\text { one diagnosis per patient possible) }\end{array}$} \\
\hline $\mathrm{HCV}$ & $47 \%$ & $46 \%$ & 0.7831 & $42 \%$ & 0.0073 \\
\hline HCC & $14 \%$ & $11 \%$ & 0.2040 & $5 \%$ & $<0.0001$ \\
\hline
\end{tabular}




\begin{tabular}{|c|c|c|c|c|c|}
\hline \multirow[t]{2}{*}{ Characteristic } & \multirow{2}{*}{$\begin{array}{c}\text { Potential Recipients } \\
\text { With } \\
\text { at Least One Donor } \\
\text { Accepted (n= 401) } \\
\\
\begin{array}{c}\text { Mean (SD) or } \\
\text { Percent }\end{array}\end{array}$} & \multirow{2}{*}{$\begin{array}{c}\begin{array}{c}\text { Potential Recipients } \\
\text { With } \\
\text { No Donors Accepted } \\
(\mathrm{n}=418)\end{array} \\
\begin{array}{c}\text { Mean (SD) or } \\
\text { Percent }\end{array}\end{array}$} & \multirow[t]{2}{*}{$\begin{array}{c}\boldsymbol{P} \\
\text { Value }^{\dagger}\end{array}$} & \multirow{2}{*}{$\begin{array}{c}\begin{array}{c}\text { DDLT Waitlist } \\
\text { Candidates } \\
\text { Not Considered for } \\
\text { LDLT } \\
(\mathbf{n}=\mathbf{7 , 3 5 8})\end{array} \\
\begin{array}{c}\text { Mean (SD) or } \\
\text { Percent }\end{array}\end{array}$} & \multirow[t]{2}{*}{$P$ Value } \\
\hline & & & & & \\
\hline Alcohol & $13 \%$ & $15 \%$ & 0.3862 & $16 \%$ & 0.2699 \\
\hline Cholestatic liver disease & $18 \%$ & $19 \%$ & 0.7275 & $10 \%$ & $<0.0001$ \\
\hline $\begin{array}{l}\text { Noncholestatic cirrhosis other than HCV/ } \\
\text { alcohol }\end{array}$ & $21 \%$ & $20 \%$ & 0.8327 & $21 \%$ & 0.5761 \\
\hline Metabolic disease & $3 \%$ & $3 \%$ & 0.7556 & $2 \%$ & 0.0995 \\
\hline Biliary atresia & $1 \%$ & $0 \%$ & 0.0765 & $<1 \%$ & 0.2941 \\
\hline Malignancy other than HCC & $3 \%$ & $2 \%$ & 0.3174 & $<1 \%$ & $<0.0001$ \\
\hline Fulminant & $2 \%$ & $1 \%$ & 0.1124 & $6 \%$ & $<0.0001$ \\
\hline Other & $3 \%$ & $4 \%$ & 0.4903 & $6 \%$ & $<0.0017$ \\
\hline Ascites * & $61 \%$ & $68 \%$ & 0.0297 & $65 \%$ & 0.4920 \\
\hline Variceal bleed * & $17 \%$ & $19 \%$ & 0.5211 & $5 \%$ & $<0.0001$ \\
\hline Upper abdominal surgery $*$ & $19 \%$ & $20 \%$ & 0.9234 & $27 \%$ & $<0.0001$ \\
\hline Spontaneous bacterial peritonitis * & $8 \%$ & $5 \%$ & 0.1509 & $6 \%$ & 0.4725 \\
\hline $\begin{array}{l}\text { Transjugular intrahepatic portosystemic } \\
\text { shunt * }\end{array}$ & $9 \%$ & $12 \%$ & 0.0711 & $5 \%$ & $<0.0001$ \\
\hline MELD & & & 0.0388 & & \\
\hline Pre-MELD period & $15.5(7.1)$ & $16.0(7.2)$ & & N/A & N/A \\
\hline Post-MELD period & $14.5(5.4)$ & $17.1(7.2)$ & & $15.8(8.3)$ & 0.6249 \\
\hline MELD categories $\xi$ & & & 0.0558 & & \\
\hline $6-10$ & $25 \%$ & $20 \%$ & & $26 \%$ & \\
\hline $11-20$ & $58 \%$ & $56 \%$ & & $54 \%$ & \\
\hline $21-30$ & $13 \%$ & $18 \%$ & & $10 \%$ & \\
\hline $31-40$ & $4 \%$ & $6 \%$ & & $9 \%$ & \\
\hline Recipient medical condition * & & & 0.9274 & & 0.0094 \\
\hline $\mathrm{ICU}$ & $4 \%$ & $3 \%$ & & $5 \%$ & \\
\hline Hospitalization, no ICU & $7 \%$ & $8 \%$ & & $6 \%$ & \\
\hline Not hospitalized & $89 \%$ & $89 \%$ & & $89 \%$ & \\
\hline Mechanical ventilation * & $2 \%$ & $2 \%$ & 0.7359 & $3 \%$ & 0.2044 \\
\hline Renal failure requiring dialysis * & $4 \%$ & $3 \%$ & 0.7744 & $2 \%$ & 0.0581 \\
\hline Diabetes mellitus * & $19 \%$ & $21 \%$ & 0.4247 & $19 \%$ & 0.5736 \\
\hline Angina/coronary artery disease $*$ & $3 \%$ & $5 \%$ & 0.2503 & $2 \%$ & 0.0192 \\
\hline Drug treated systemic hypertension $*$ & $12 \%$ & $13 \%$ & 0.7686 & $13 \%$ & 0.8236 \\
\hline Days from listing to first donor evaluation & $194.9(303.3)$ & $258.5(352.3)$ & 0.0059 & N/A & N/A \\
\hline $\begin{array}{l}\text { Number of evaluated donors per recipient } \\
*\end{array}$ & & & 0.5662 & & N/A \\
\hline 1 & $83 \%$ & $81 \%$ & & N/A & \\
\hline 2 & $14 \%$ & $15 \%$ & & N/A & \\
\hline
\end{tabular}




\begin{tabular}{|c|c|c|c|c|c|}
\hline \multirow[t]{2}{*}{ Characteristic } & \multirow{2}{*}{ 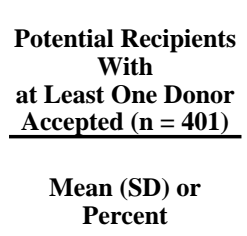 } & \multirow{2}{*}{$\begin{array}{c}\begin{array}{c}\text { Potential Recipients } \\
\text { With } \\
\text { No Donors Accepted } \\
(\mathrm{n}=418)\end{array} \\
\begin{array}{c}\text { Mean (SD) or } \\
\text { Percent }\end{array}\end{array}$} & \multirow[t]{2}{*}{$\begin{array}{c}\boldsymbol{P} \\
\text { Value }^{\dagger}\end{array}$} & \multirow{2}{*}{$\begin{array}{c}\begin{array}{c}\text { DDLT Waitlist } \\
\text { Candidates } \\
\text { Not Considered for } \\
\text { LDLT } \\
(\mathbf{n}=\mathbf{7 , 3 5 8})\end{array} \\
\begin{array}{c}\text { Mean (SD) or } \\
\text { Percent }\end{array}\end{array}$} & \multirow[t]{2}{*}{$P$ Value } \\
\hline & & & & & \\
\hline $3-7$ & $3 \%$ & $4 \%$ & & N/A & \\
\hline \multicolumn{6}{|c|}{ Missing at most $3 \%$. } \\
\hline \multicolumn{6}{|c|}{ Recipients with at least 1 donor accepted versus recipients with no accepted donor. } \\
\hline \multicolumn{6}{|c|}{${ }^{*}$ All potential LDLT recipients versus DDLT waitlist candidates not considered for LDLT. } \\
\hline
\end{tabular}




\section{Table 3}

Disposition of A2ALL Potential Donors $(\mathrm{n}=1011)$

\begin{tabular}{lc}
\hline Characteristic & $\mathbf{n}(\boldsymbol{\%})$ \\
\hline Potential Donors Who Were Not Accepted & $\mathbf{6 0 6}(\mathbf{6 0 \%})$ \\
Donor-related reasons & \\
Medical contraindictions & $173(17 \%)$ \\
Anatomical contraindications & $115(11 \%)$ \\
Donor liver steatosis & $65(6 \%)$ \\
Declined to donate & $68(7 \%)$ \\
Psychosocial contraindications & $55(5 \%)$ \\
Recipient-related reasons & \\
Recipient received DDLT & $65(6 \%)$ \\
Recipient died & $24(2 \%)$ \\
Recipient too sick/removed from transplant consideration & $19(2 \%)$ \\
Recipient improved & $8(1 \%)$ \\
Recipient declined/refused organ & $5(<1 \%)$ \\
Other/unknown & $9(1 \%)$ \\
Potential donors who were accepted & $\mathbf{4 0 5}(\mathbf{4 0 \%})$ \\
Successful donation & $392(39 \%)$ \\
Went to operating room but procedure aborted & $12(1 \%)$ \\
Graft resected but not transplanted & $1(<1 \%)$ \\
\hline
\end{tabular}


Table 4

Logistic Regression Model of Donor Acceptance

\begin{tabular}{|c|c|c|c|c|}
\hline Variable* & Adjusted Odds Ratio & 95\% Confidence & Limits & $P$ Value \\
\hline \multicolumn{5}{|l|}{ Donor age } \\
\hline $18 \leq$ donor age $<40$ & 1.00 & & & Reference \\
\hline $40 \leq$ donor age $<50$ & 0.81 & 0.57 & 1.14 & 0.2256 \\
\hline $50 \leq$ donor age $<60$ & 0.61 & 0.38 & 0.96 & 0.0332 \\
\hline \multicolumn{5}{|l|}{ Donor BMI } \\
\hline BMI $\leq 24.9$ & 1.00 & & & Reference \\
\hline $25.0 \leq \mathrm{BMI} \leq 29.9$ & 0.77 & 0.55 & 1.06 & 0.1118 \\
\hline BMI $\geq 30$ & 0.31 & 0.20 & 0.47 & $<0.0001$ \\
\hline \multicolumn{5}{|l|}{ Relatedness to recipient } \\
\hline Biologically related/Spouse & 1.51 & 1.05 & 2.16 & 0.0258 \\
\hline Nonbiological (excluding spouse) & 1.00 & & & Reference \\
\hline \multicolumn{5}{|l|}{ Era of donor evaluation } \\
\hline $1998-2000$ & 2.03 & 1.48 & 2.79 & $<0.0001$ \\
\hline 2001-2003 & 1.00 & & & Reference \\
\hline \multicolumn{5}{|l|}{ Recipient age } \\
\hline 18 srecipient age $<30$ & 2.08 & 1.17 & 3.72 & 0.0132 \\
\hline $30 \leq$ recipient age $<50$ & 1.37 & 1.01 & 1.87 & 0.0446 \\
\hline $50 \leq$ recipient age $<76$ & 1.00 & & & Reference \\
\hline \multicolumn{5}{|l|}{ Recipient MELD } \\
\hline $6 \leq$ MELD $\leq 10$ & 1.85 & 1.17 & 2.93 & 0.0081 \\
\hline $11 \leq$ MELD $\leq 20$ & 1.77 & 1.18 & 2.67 & 0.0063 \\
\hline $21 \leq \mathrm{MELD} \leq 40$ & 1.00 & & & Reference \\
\hline \multicolumn{5}{|c|}{ Days from recipient listing to first donor evaluation } \\
\hline$<23$ Days & 1.66 & 1.16 & 2.36 & 0.0052 \\
\hline$\geq 23$ Days & 1.00 & & & Reference \\
\hline \multicolumn{5}{|l|}{ A2ALL center } \\
\hline Range of ORs among 9 centers & $0.26-2.44$ & & & $<0.0001$ \\
\hline Average over all A2ALL centers & 1.00 & & & Reference \\
\hline
\end{tabular}

* Variables tested and excluded from the model included: donor gender, donor ethnicity, donor race, donor alkaline phosphatase, donor bilirubin, donor case number, number of evaluated donors per recipient, order of donors evaluated per recipient, recipient gender, recipient ethnicity, recipient race, recipient diagnosis, recipient BMI, donor-recipient ethnicity match, and estimated graft weight-recipient weight ratio. 